\title{
SOME OBSERVATIONS OF THE HYDROLOGY AND PLANKTON OF THE NORTH SEA AND ENGLISH CHANNEL
}

\author{
By Michael Graham, M.A., and J. P. Harding, Ph.D. \\ Fisheries Laboratory, Lowestoft
}

(Text-figs. I-4)

In April 1935 a vacant period in the programme of the research vessel George Bligh was occupied in determining the phosphate content of the waters of a selected line of stations in the North Sea and English Channel. The object was to extend the usual observations of phosphate in the North Sea, which form the subject of a separate paper (Graham, I938), in the directions from which the southern North Sea receives its more oceanic water. It was thought in particular that observations between the southern North Sea and the area regularly examined from the laboratory at Plymouth would have an intrinsic interest. The distribution of the phosphate found in 1935 seemed to be of sufficient interest to warrant repetition of the experiment in 1936 and again in 1937 .

Observations were made along the line drawn on the chart (Fig. I). The positions marked I-XV on this chart correspond to the vertical lines I-XV in Figs. 2-4. The stations at which the observations were actually made lie near this line in positions indicated by circles in Figs. 2-4. The exact positions have been published in the Bulletin Hydrographique of the International Council for the cruises of the George Bligh April 26-30 1935, and May I3-I8 I936, and will be published for the cruise April 8-I5 1937 .

Temperature, salinity and phosphate determinations were recorded at $10 \mathrm{~m}$. intervals from surface to near bottom at each station, and samples of the plankton were taken with Hensen's net.

The phosphate content was determined in 1935 by the Atkins-Denigés method, as recommended by the conference which met in Oslo in 1928, recorded in the Rapports et Procés-Verbaux des Réunions du Conseil International, Vol. LIII, pp. 96-Ioo. In 1936 and 1937 the phosphate was determined with the "Lowestoft Photometer" (Graham, I936).

The season at which it was possible to do this work was not particularly suitable because the phosphate content of the water was changing rapidly near the spring outburst of diatoms. Nevertheless, certain features have been repeated. There is a tendency for areas of high phosphate content to be associated with extremes of salinity and temperature, and three sources of phosphate are recognized: (i) A trough of cool deep water connecting the 


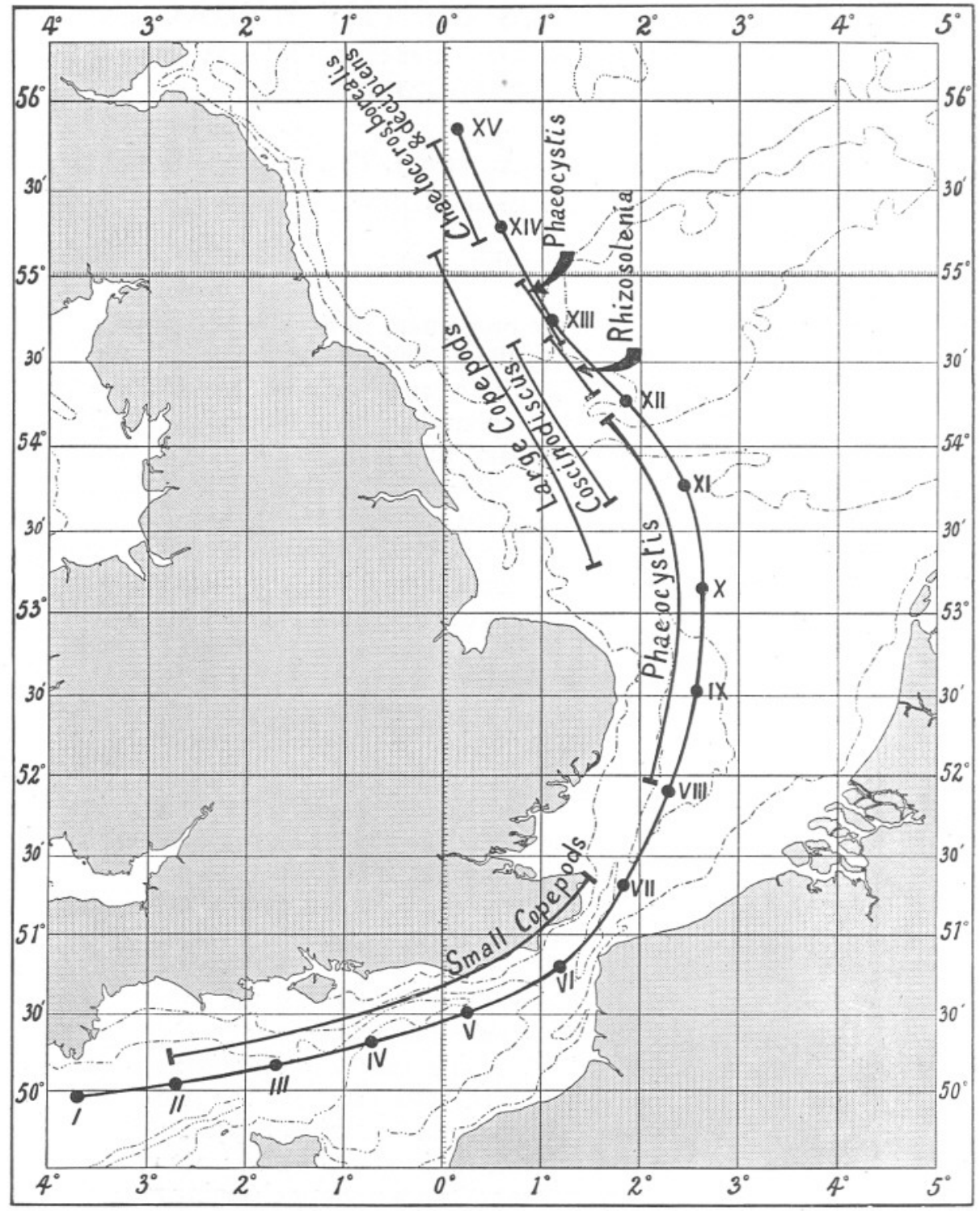

Fig. I. 


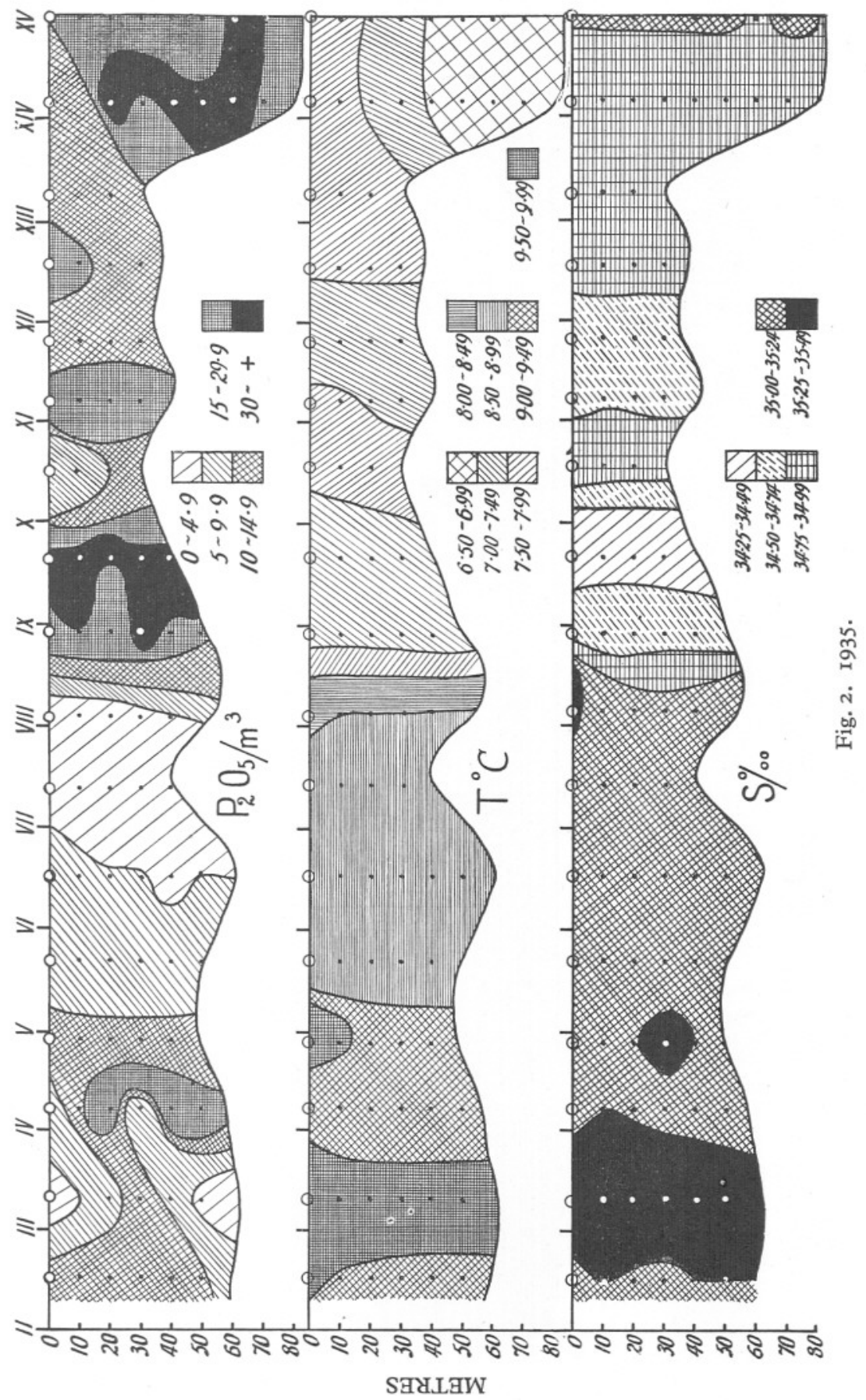




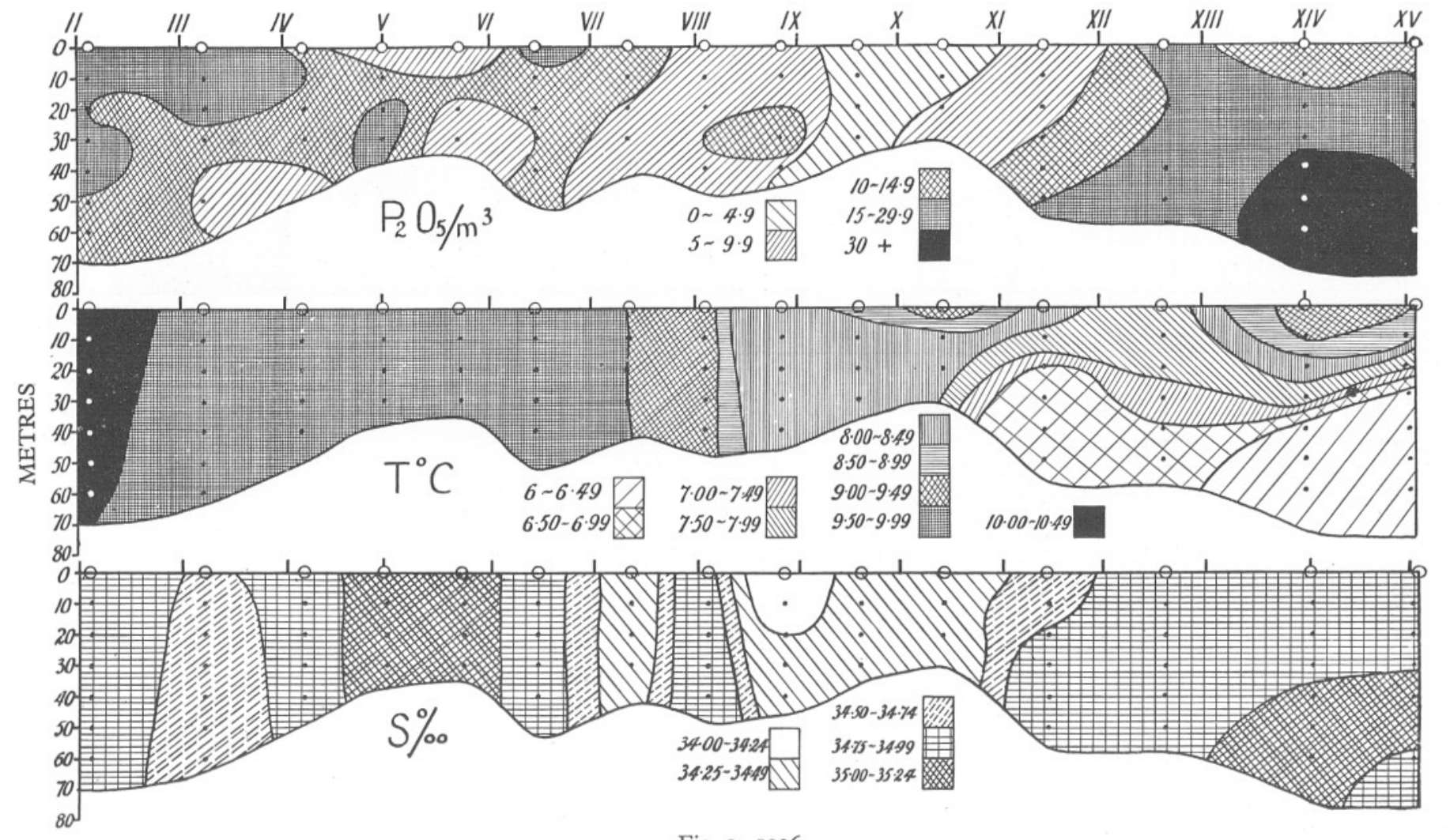

Fig. 3. 1936. 
southern North Sea with the more oceanic water of the northern North Sea, which was found to have a high phosphate content; (ii) Irregular areas of high phosphate content in the warmer Channel waters, which may be assumed to be oceanic in origin; and (iii) An area of low salinity about position IX, which was found to have a high phosphate content. This area was most pronounced in April 1935 and April 1937, and there was some indication of it in May I936. The water here tended to be a little cooler than the surrounding

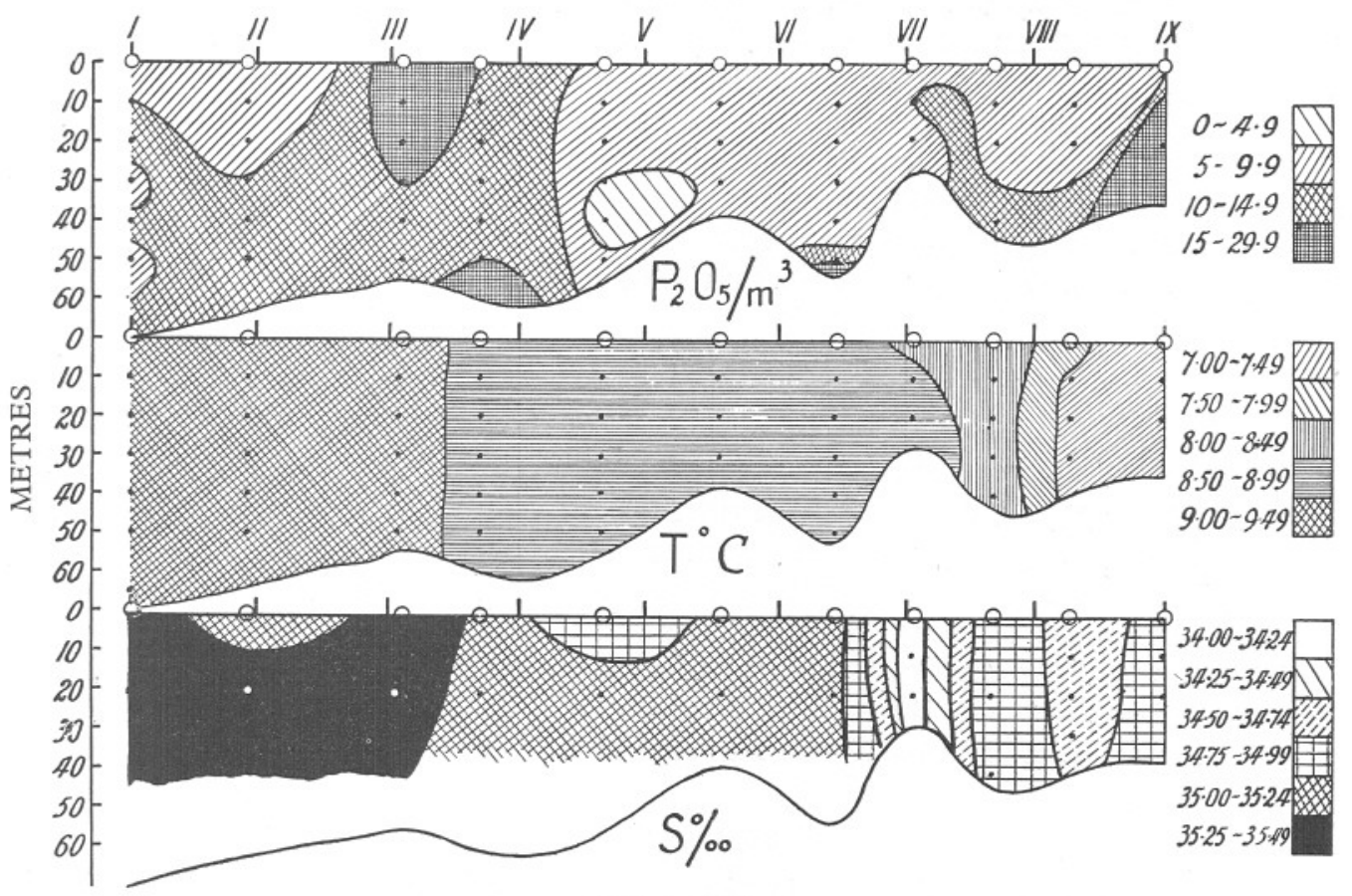

Fig. 4. I937.

water. The interpretation of these features is helped by the observations of other cruises. The high phosphate content of the northern part is ascribed to accumulation of phosphate under the thermocline, indications of which are present even at this early season. In the same way the high phosphate associated with low salinity in part of the southern North Sea is recognized as similar to areas of high phosphate found in other cruises and ascribed to the sewage of the River Thames. In regard to the Channel, the records from Plymouth for the International hydrographic station E I (Atkins, I930; Cooper, I933; and Harvey et al. I935, and more recent records from the Bulletin Hydrographique) show that the phosphate near the bottom of this part of the Channel is rarely less than Io mg. $\mathrm{P}_{2} \mathrm{O}_{5} / \mathrm{m}^{3}$ This condition is found to extend up the Channel but is lost near the Straits of Dover, where the water tends to 
have very low concentration. There is no obvious explanation of why phosphate in the Channel does not reach the North Sea.

In regard to the larger plankton organisms that are taken in Hensen's net, the main features were also repeated in all three years. The distribution found in the 1935 Hensen samples is shown in Fig. I. It is seen that the Channel, Southern Bight and the more northern part of the section have characteristic plankton populations. This distribution was repeated in 1936 and 1937 with the following modifications: in 1936, small copepods were found in the northern positions XI-XV as well as in the Channel positions II-VII. Small copepods were also found in all stations in 1937, but owing to pressure on the ship's time these stations did not extend farther north than position IX. Phaeocystis was found farther south in 1936 than in 1935 in positions V-XII, and in 1937 it was practically absent, traces only being found in position VIII. The area of large copepods was restricted to position XV in 1936, though it had extended as far south as position X in 1935 .

\section{SUMMARY}

Phosphate, salinity and temperature records of waters of the North Sea and English Channel have been compared for April or May in the years I935, 1936 and 1937, and the plankton distribution has been noted. Attention is called to the appearance of stability in certain features.

Thus, a high phosphate content was found to be associated with extremes of salinity and temperature, in similar areas in each year. The phosphate appears to be brought into the North Sea and Channel by oceanic water and by drainage from the land.

The plankton organisms were also similarly distributed in each year.

\section{REFERENCES}

Atkins, W. R. G., I930. Seasonal variations in the phosphate and silicate content of sea water in relation to the phytoplankton crop. Part V. November 1927 to April 1929, compared with earlier years from 1923. Fourn. Mar. Biol. Assoc., Vol. XVI, pp. 82I-52.

Cooper, L. H. N., I933. Chemical constituents of biological importance in the English Channel, November 1930 to January 1932. Part I. Phosphate, silicate, nitrate, nitrite, ammonia. Fourn. Mar. Biol. Assoc. Vol. xviII, pp. 677-728.

Graham, M., 1936. The Lowestoft Photometer. Fourn. Cons. Int. Expl. Mer, Vol. xi, pp. 205-10.

I938. Phytoplankton and the herring. Part III. Distribution of phosphate in I934-6. Min. Agric. Fish., Fish. Invest., Ser. II, Vol. xvi, No. 3, pp. I-26.

Harvey, H. W., Cooper, L. H. N., Lebour, M. V. \& Russell, F. S., I935. Plankton production and its control. fourn. Mar. Biol. Assoc., Vol. xx, pp. 407-4I. 